\title{
Tıbbi Aromatik Bitki Çirişotu ( Asphodeline taurica) Özütünün Kayın Odununda Emprenye Edilebilme Yeteneği ve Bazı Teknolojik Özelliklere Etkisi
}

\author{
Hatice Ulusoy $^{1 *}$, Hüseyin Peker ${ }^{2}$ \\ ${ }^{1}$ Muğla Sttkı Koçman Üniversitesi, Köyceğiz Meslek Yüksekokulu, Muğla, Turkey (ORCID:0000-0003-0960-3388) \\ ${ }^{2}$ Artvin Çoruh Üniversitesi, Orman Fakültesi, Artvin, Turkey (ORCID:0000-0002-7771-6993) \\ (Bu yayın 26-27 Haziran 2020 tarihinde HORA-2020 kongresinde sözlü olarak sunulmuştur.)
}

(DOI: 10.31590/ejosat.779692)

\begin{abstract}
ATIF/REFERENCE: Ulusoy, H. \& Peker, H. (2020). Tıbbi Aromatik Bitki Çirişotu ( Asphodeline taurica ) Özütünün Kayın Odununda Emprenye Edilebilme Yeteneği ve Bazı Teknolojik Özelliklere Etkisi. Avrupa Bilim ve Teknoloji Dergisi, (Special Issue), 199-203.
\end{abstract}

Öz

Ülkemiz ve insanın var olduğu her ortamda doğuştan son ana kadar ahşabın kullanımı / korunması büyük önem taşımaktadır. Bütün bunların yanında insan/çevre sağlık bilinci tüm yönleriyle günümüzde dahada büyük önem kazanmıştır. Tıbbi aromatic bitkiler birçok yönüyle analiz edilmesine karşın insanın yoğunca kullandığı ahşapla irtibatlanmamıştır. Bu amaçla antioksidant/antibakteriyel özelliği belirlenmiş çiriş otunun \%1-3 oranında özütü hazırlanmak suretiyle (su çözücü) kayın odununa (Fagus oreintalis Lipsky) ASTM D 1413-76 standartı doğrultusunda emprenyeler (20-30 dakika vakum ve 20/30 dakika difuzyon süresi) uygulanmıştır.

Deney sonuçlarına gore; en yüksek \% retensiyon \%3 'lük çiriş çözeltisinde 20 dakika vakum 20 dakika difüzyonda (\% 0.43) ,en düşük (\%1) \% retensiyon 20 dakika vakum 20 dakika difüzyonda (\%0.09) tespit edilmiştir. En yüksek dinamik eğilme direnci \%3 çiriş özütünde 20 dakika vakum $/ 20$ dakika difüzyonda $(0.66 \mathrm{~N} / \mathrm{mm} 2)$, en düşük dinamik eğilme direnci \% 3 çiriş özütünde 20 dakika vakum $/ 30$ dakika difüzyonda $(0.57 \mathrm{~N} / \mathrm{mm} 2)$ belirlenmiştir. Bu durum odun türü, anatomik yap1, emprenye maddesi, emprenye türünün dinamik eğilme direnci üzerinde etkili olduğunu söyleyebiliriz. Kontrol örneğine oranla küçükte olsa bir yükselme vardır.

Anahtar Kelimeler-Tıbbi aromatik bitki, çiriş bitkisi, Kayın odunu, teknolojik özellikler, ahşap/mobilya endüstrisi.

\section{The Impact of Medicinal Aromatic Herbal Caperella (Asphodeline taurica) Extract on Beech Wood and Some Technological PropertiesWood}

\begin{abstract}
Today, various technological features have been tried to be determined by making impregnation on beech wood in order to create an antioxidant / antibacterial structure in the wood structure, which is organic, to get completely natural impregnation material / top surface material and to produce indoor / outdoor furniture (wooden toys, hospitals, hygienic environments. , laboratories, etc.) to determine the parameters for use in the industry. For this purpose, the impregnation process (20-30 minutes vacuum and 20/30 minutes diffusion time) according to the principles of ASTM D 1413-76 (water solvent) beech wood (Fagus oreintalis Lipsky) by preparing 1-3\% extract of the herb, whose antioxidant / antibacterial properties are determined) has been implemented.
\end{abstract}

* Sorumlu Yazar: Muğla Sitkı Koçman Üniversitesi, Köyceğiz Meslek Yüksekokulu, Muğla, Turkey ORCID:0000-0003-0960-3388, haticeulusoy@mu.edu.tr 
According to the results of the experiment; $20 \%$ vacuum in $20 \%$ diffusion $(0.43 \%)$, the lowest (1\%) retention 20 minutes in vacuum 20 minutes diffusion $(0.09 \%)$ in the $3 \%$ solution solution. The highest dynamic bending resistance was determined at $20 \%$ vacuum / 20 minutes diffusion $\left(0.66 \mathrm{~N} / \mathrm{mm}^{2}\right)$ at $3 \%$ gross extract, the lowest dynamic bending resistance was determined at 20 minutes vacuum / 30 minutes diffusion $\left(0.57 \mathrm{~N} / \mathrm{mm}^{2}\right)$ at $3 \%$ gross extract. This situation can be said that wood type, anatomical structure, impregnation agent, impregnation type are effective on dynamic bending resistance. There is a slight increase compared to the control sample

Keywords: Larex wood, mechanical properties, wood / furniture industry, impregnation, stone water.

\section{Giriş}

Yeryüzünde insan sağlığının tedavisinde gerek tıbbi amaçlı ve gerekse baharat endüstrisinde kullanılmaya devam edilen yaklaşık bitki envanterinin 20.000 dolayında varolduğunu Dünya Sağlık Örgütü (WHO) bildirmiştir. Günümüzde doğal ortamda varolan 300 civarında bitki türevinin 1/3'ü uçucu yağ asidi içerdiği bilinmektedir. Lamiaceae familyasına ait bitkilerdeki (Origanum, Thymus, Ocimum, Mentha, Rosmarinus, Sideritis, Salvia) uçucu yağların çeşitli maya/bakteri gelişimini engellediği ve bu yapısından dolayı yiyeceklerde doğal yapının korunduğu bilinen bir gerçektir. Bitki ekstraktlarının ilaç üretiminde kullanıldığı Çin'de M.Ö. 2700 yıllara değin gitmektedir. Gerek dünyada ve gerek ülkemizde yapılan çok çeşitli çalışmalarla insanlar içinde şifalı olarak bilinen bitkilerçok çeşitli hastalıkların tedavisinde kullanılagelmektedir. Anadoluda yabani olarak bilinen bitkilerin ilaç olarak kullanımı geçmişlere değin gitmektedir. Hitit uygarlığında yazılı tabletlerde çok çeşitli ilaç karışımları/reçeteler/ formüller ve aynı zamanda belgelere geçmiş bitki isimleri yer almaktadır. Yaklaşık 500 civarında olanının ticaret ortamında değerlendirildiği bildirilmiştir. Ülkemiz ilaç sanayinde kayıtlara geçen bitki miktarı 140 dolaylarında olduğu fakat bu sayının çok daha fazla olduğu bilinmektedir [1,2].

İnsanoğlu varoluşundan yakın zamana kadar giyim, barınma, yiyecek ve yakacak gibi neredeyse bütün ihtiyaçlarını ormanların sınırları içerisinden temin etmekteydi. Fakat günümüzde teknoloji, ormancılık yöntemi ve orman işletmeciliğinin gelişimi, insanların ormanlardan elde ettiği ihtiyaçlarını yalnızca odun hammaddesi üzerine yoğunlaştırmıştır. Ülkemizde de gün geçtikçe bu anlayış hakim olmaya başlamış ve odun (tomruk, kereste, vs.) üretimiyle sınırlı kalmaya başlamıştır. Halbuki ormanlık alanlar bünyesindeki ağaç serveti dışında içerisinde birçok otsu bitki, yaban hayvanları, su kaynakları, rekreasyon alanları gibi birçok ekonomik ve kültürel faaliyetlerin bir arada yürütülebileceği ve sağlıklı bir yaşam için eşi bulunmaz bir kaynaktır [3].

Anadolu insanı yontma taş devrinden günümüze kadar bitkileri tıbbi amaçlı kullanmıştır. M.Ö. 50.000 yıllarına ait olduğu düşünülen ve Hakkari'nin Şanidar Mağarasında bulunan bir Neanderthal mezarından çıkan bitki örnekleri bu varsayımın sağlam kanıtıdır. Anadolu'da yetişen tıbbi bitkiler hakkında bulunan en eski yazılı çevrilmiş, beş kısımdan meydana gelen bu yapıtta beşyüz civarında tıbbi bitkinin morfoloji, formokoloji ve toksikoloji yapısı verilmiştir. Son yıllarda tıbbi bitkiler ve bunların üzerindeki çalışmalara karşı duyulan ilgi çok artmıştır. Bu ilginin artmasının nedenlerinden başlıcaları, sentetik ilaçların çok pahalı olmaları, birçok yan etkilerinin bulunması ve her hastalığ 1 tedavi etme niteliğine de sahip olmayışıdır [4].

Günümüzde dünyada yaklaşık 1.000 .000 civarında bitkinin var olduğu tahmin edilmektedir. Bu türlerin 500.000'e yakını tanımlanıp isimlendirilmiş, bunlarında 20.000 kadarı Dünya Sağlık Örgütü (WHO) tarafindan yapılan araştırmalar neticesinde tedavi amaçlı kullanılan tıbbi bitkilerden oluştuğu tespit edilmiştir. Ülkemizde tedavi amaçlı kullanılan tıbbi bitki miktarı en az 500 kadardır $[5]$.

Tıbbi ve aromatik bitkiler günümüzde ticareti yapılan bitkilerin önemli bir bölümünü teşkil eder. Ticarette yer alan bu bitki türlerinin büyük bir kısmı doğadan toplanırken çok azı tarlada üretilerek değerlendirilir. Hastalıkların tedavisinde kullanılmak üzere yeni etken maddelerin bulunması, bitkiler üzerindeki araştırmaların devamına bağlıdır. 1985 yılında yürütülen çalışmalar sonucu elde edilen 3500 yeni etken madde arasında 2618'inin bitkisel kökenli olduğu belirlenmiştir. Bitkiler üzerinde sürdürülecek bu tür araştırmalarla kanser gibi henüz tam olarak çaresi bulunamayan hastalıkların tedavisinde kullanılabilecek etken maddelere ulaşmak mümkün olabilecektir. İnsanoğlunun doğadan toplayarak elde ettikleri bu bitkileri koruma-kullanma prensibi ile faydalanmaya özen göstermesi gerekmektedir $[6]$.

Dünya geneline bakıldığı zaman hastalıklarla mücadele, ülke nüfuslarının çok büyük bir kısmının yabani olarak toplanan veya doğal ortamlarından alınıp tarım alanlarında yetiştiriciliği yapılan bitkilerle yapıldığı bilinmektedir. Günümüzde kullanılan sentetik ilaçların hem yetersiz kalması hem de yan etkilerinin azımsanamayacak kadar fazla olduğu görülmektedir. Buna bağlı olarak günümüzde sentetik antioksidanlar ile antibiyotiklere karşı olan güvenin gün geçtikçe azaldığı da bilinen bir gerçektir [7].

Geçmişten günümüze ahşap malzeme doğal oluşu, organik yapısı ve üstün özelliklere sahip olması nedeniyle birçok alanda (yapı, yat, tekne, ev mobilyaları vb.) tercih edilmektedir. Ahşap malzemenin ekolojik, yenilenebilir ve sürdürülebilir doğal bir kaynak olmasının yanı sıra; sağlıklı, estetik, dayanıklı ve yanmaya karşı dayanımı da onu üstün kılan özelliklerdendir. Fakat ahşap malzeme, dış hava koşullarından ve mevsimsel hava değişimlerinden olumsuz etkilenmekte, değeri ve kullanım ömrü azalmaktadır [8]

Günümüzde kimyasal apırlık malzemelerden uzaklaşıp tamamen doğal emprenye maddesi/ üst yüzey malzemesi elde etmek organik olan odun yapısında antioksidant/antibakteriyel yapı oluşturmak amacıyla kayın odununda emprenye yapılmak suretiyle çeşitli teknolojik özellikler belirlenmeye çalışılmış ve iç/dış mekan mobilya (ahşap oyuncak, hastaneler, hijyen gerektiren ortamlar, laboratuvarlar vb) endüstrisinde kullanımına yönelik paremetrelerin ortaya konması amaçlanmıştır. 


\section{Materyal ve Yöntem}

\subsection{Materyal}

Çalışma kapsamında ülkemiz odun türlerinden ve ahşap sanayiinde en çok tercih edilen kayın odunu tercih edilmiş ve TS 53,TS 2470 esasları doğrultusunda örnek kesimleri radyal yönde diri odun kısımlarından elde edilmiştir. Emprenye materyali olarak tıbbi aromatik bitkilerinden çiriş bitkisinden elde edilen özüt(ekstrakt) kullanılmıştır [9,10].

\subsection{Yöntem}

\subsubsection{Deney Örnek Hazırlı̆̆ı}

Deney örnek hazırlığında belirtilen standartlara gore kesimler gerçekleştirilmiştir.Tüm örneklerin lifsel yapısı düzgünlüğü, çatlak, budak, renksel bozukluklar (mantar, çürüklük vb) olmamasına özen gösterilmiştir. Tutunma düzeyinin tesbitinde 100x50x30 mm ölçüsünde deney örnekleri hazırlanırken [11] dinamik eğilme değişiminin belirlenmesinde TS 2477 standartına (300x20x20 mm) göre işlem gerçekleştirilmiştir [12].

\subsection{2. Özüt (Ekstrakt) Hazırlama}

Deney için belirlenen örnek ağırlığı 200 ml sıcak damıtılmış su veya en az bu saflığa denk bir su içerisine konarak belli aralıklarla karıştırılmak suretiyle 1 saat süre geri soğutuculu düzenekte kaynama noktasının altında bir sıcaklıkta 1sıtılmış, önceden hazırlanmış gözenekli kapsül içerisinde vakum eşliğinde süzüldükten sonra balon içerisinde numune kalmayacak şekilde birkaç kez damıtılmış su ile yıkanacak şekilde işleme devam edilmiş ve çözünmeyen kısım tamamıyla gözenekli kapsül içerisine bırakılmıştır. Son olarak kalıntı $200 \mathrm{ml}$ sıcak damıtılmış su ile yıkanmış ve kalıntının bir pompa veya emme vazifesi görecek bir başka cihaz yardımıyla suyu alındıktan sonra gözenekli kapsül ve içerenindekiler $103 \mathrm{oC}$ 'de ayarlı etüv içerisinde 16 saat tutulmak suretiyle kurutulduktan sonra desikatörde soğutulmuş ve $0.001 \mathrm{~g}$ hassasiyetle tartım işlemi yapılmıştır [13].

\subsubsection{Emprenye}

Emprenyede ASTM-D 1413-76 esaslar dahilinde yapılmıştır. 30 dakika vakum ve 30 dakika difüzyon süresi uygulanmıştır. Emprenye maddesinin odun rutubetinden etkilenmemesi için deney örnekleri tam kuru hale getirilmiştir .Örnekler emprenye ve difüzyon işleminden sonra bir süre hava kurusu ortamda bekletilmiştir. Tüm örneklerin ilk ölçüm ve tartımları yapılmış daha sonra etüvde $103 \pm 2^{\circ} \mathrm{C}^{\prime}$ de 24 saat sonunda tam kuru tartım/ölçüm alınmış ve akabinde vakumlu emprenye işlemi yapılmıştır [14].

\subsubsection{Net Kuru Madde Miktarı (\% retensiyon)}

Emprenye işleminden sonra tam kuru odun ağırlığına oranla kalan madde miktarı (tkoao-\% retensiyon) belirtilen formülle hesaplanmıştır [15].

$$
\begin{aligned}
& R(\%)=\frac{\text { Moes }- \text { Moeö }}{\text { Moeё }} \times 100 \\
& \text { Moes = Emprenye sonrası örnek tam kuru ă̆ırliğl (g) } \\
& \text { Moë̈= Emprenye öncesi örnek tam kuru ă̆lrlı̆̆l (g) }
\end{aligned}
$$

\subsubsection{Dinamik Eğilme Direnci (Şok)}

Dinamik Eğilme (Şok) direncinde işlemlerde TS 2477 esaslarına uyulmuş . Örnek ölçüleri 2x2x30cm olarak hazırlandıktan sonra klimatize edilmiş " $20 \pm 2{ }^{\circ} \mathrm{C}$ ve $\% 65 \pm 5$ bağıl nemde bırakılarak odun rutubetinin "\%12” ye getirilmiştir. Tüm örneklerin ölçümler her bir parçanın orta noktası dikkate alınarak gerçekleştirilmiş "radyal/teğet/boy” böylelikle şok direnci (dinamik eğilme) deneylerine hazır hale getirilmiştir [12].

\section{Bulgular veTartışma 3.1. Çözelti Özellikleri}

Çözelti özelliklerine ilişkin bulgular Tablo 1'de verilmiştir. 
Avrupa Bilim ve Teknoloji Dergisi

Tablo 1. Ç̈̈zelti Özellikleri

\begin{tabular}{|c|c|c|c|c|c|c|}
\hline \multirow{2}{*}{ Emprenye Maddesi } & \multirow{2}{*}{$\begin{array}{c}\text { Çözücü } \\
\text { Madde }\end{array}$} & \multirow{2}{*}{$\begin{array}{c}\text { Sıcaklık } \\
\left({ }^{\circ} \mathbf{C}\right)\end{array}$} & \multicolumn{2}{|c|}{ Ph } & $\begin{array}{c}\text { Yoğunluk } \\
\text { (g/ml) }\end{array}$ & Yoğunluk (g/ml) \\
\cline { 4 - 7 } & & & Ë̈ & ES & EÖ & ES \\
\hline Çiriş Bitki Özütü \%1 & DS & $22^{\circ} \mathrm{C}$ & 6.15 & 6.18 & 0.792 & 0.792 \\
\hline Çiriş Bitki Özütü \%3 & DS & $22^{\circ} \mathrm{C}$ & 6.86 & 6.86 & 0.798 & 0.798 \\
\hline
\end{tabular}

DS: Destile su

Emprenye işleminden öncesi ve sonrasında $\mathrm{pH}$ ve yoğunluklarda küçük değişiklikler gözlenmiş olup ; bunun odun türünden ve emprenye maddesinden kaynaklandığını söyleyebiliriz.

\section{2. \%Retensiyon (Tutunma)}

Tutunma (\%retensiyon/net kuru emprenye maddesi miktarı) Tablo 2'de verilmiştir.

Tablo 2. \% Retensiyon Değgerleri

\begin{tabular}{|c|c|c|c|c|c|}
\hline $\begin{array}{l}\text { Odun } \\
\text { Türü }\end{array}$ & $\begin{array}{c}\text { Özüt } \\
\text { Konsantrasyonu }\end{array}$ & $\begin{array}{c}\text { Vakum Süresi } \\
\text { (Dakika) }\end{array}$ & $\begin{array}{l}\text { Difuzyon Süresi } \\
\text { (Dakika) }\end{array}$ & $\begin{array}{c}\text { Retensiyon } \\
(\%)\end{array}$ & HG \\
\hline \multirow{8}{*}{$\begin{array}{l}\text { Kayın } \\
\text { Odunu }\end{array}$} & \multirow{4}{*}{$\begin{array}{c}\text { Çiriş Ekstraktı } \\
(\% 1)\end{array}$} & \multirow{2}{*}{$20 \mathrm{Dk}$} & $20 \mathrm{Dk}$ & 0.09 & $\mathrm{H}$ \\
\hline & & & $30 \mathrm{Dk}$ & 0.11 & $\mathrm{G}$ \\
\hline & & \multirow{2}{*}{$30 \mathrm{Dk}$} & $20 \mathrm{Dk}$ & 0.14 & $\mathrm{~F}$ \\
\hline & & & $30 \mathrm{Dk}$ & 0.28 & $\mathrm{E}$ \\
\hline & \multirow{4}{*}{$\begin{array}{l}\text { Çiriş Ekstraktı } \\
(\% 3)\end{array}$} & \multirow{2}{*}{$20 \mathrm{Dk}$} & $20 \mathrm{Dk}$ & 0.43 & $\mathbf{A}$ \\
\hline & & & $30 \mathrm{Dk}$ & 0.40 & B \\
\hline & & \multirow[b]{2}{*}{$30 \mathrm{Dk}$} & $20 \mathrm{Dk}$ & 0.35 & $\mathrm{D}$ \\
\hline & & & $30 \mathrm{Dk}$ & 0.37 & $\mathrm{C}$ \\
\hline
\end{tabular}

En yüksek \%retensiyon (tutunma) çiriş özütünün (\%3) 20 dakika vakum 20 dakika difüzyonda ( \% 0.43) ,en düşük (\%1) \% retensiyon 20 dakika vakum 20 dakika difüzyonda $(\% 0.09)$ tespit edilmiştir.

Yapılan bir çalışmada; barit maddesinin ahşaba emprenye edilebilme özeliği ve yoğunluk üzerindeki etkileri incelenmiştir. Bu deneyler sonucunda toplam retensiyon değeri en fazla kayın odununda \% 50’lik barit çözeltisinde (20.30 kg/m3) olarak belirlenmiştir [16].

Yapılan başka bir çalışmada; çay bitkisi ile emprenye işlemine tabi tutulan ağaç malzemede toplam retensiyon ve \% retensiyonları belirlemişlerdir. İşlemleri sonucu en düşük \% retensiyonu iroko odununda (\% 1.58), en yüksek \% retensiyon oranını kayın odununda (\% 6.75) görmüşlerdir. En düşük toplam retensiyon iroko $(31.27 \mathrm{~kg} / \mathrm{m} 3)$ 'da, en yüksek toplam retensiyon değeri kayın odununda (100.65 $\mathrm{kg} / \mathrm{m} 3$ ) olduğunu bildirmişlerdir. Retensiyon sonuçlarına göre; çay bitki ekstraktından elde edilen organiklerin, ahşap malzemesinde emprenye maddesi olarak kullanılabilir olduğunu belirtmişlerdir [17].

\subsection{Dinamik Ĕgilme (Şok) Direnci $\left(\mathrm{N} / \mathrm{mm}^{2}\right)$}

Dinamik eğilme direnci değişimi ve Duncan testi sonuçları Tablo 3 ’te verilmiştir.

Tablo 3. Dinamik Eğilme Direnci $\left(\mathrm{N} / \mathrm{mm}^{2}\right)$

\begin{tabular}{|c|c|c|c|c|c|}
\hline \multirow[t]{2}{*}{$\begin{array}{l}\text { Odun } \\
\text { Türü }\end{array}$} & \multirow{2}{*}{$\begin{array}{c}\text { Özüt } \\
\text { Konsantrasyonu }\end{array}$} & \multirow{2}{*}{$\begin{array}{c}\text { Vakum } \\
\text { Süresi } \\
\text { (Dakika) }\end{array}$} & $\begin{array}{c}\text { Difuzyon Süresi } \\
\text { (Dakika) }\end{array}$ & $\begin{array}{c}\text { Dinamik Eğilme } \\
\text { Direnci }\end{array}$ & HG \\
\hline & & & Kontrol & 0.58 & $\mathrm{~F}$ \\
\hline \multirow{8}{*}{$\begin{array}{l}\text { Kayın } \\
\text { Odunu }\end{array}$} & \multirow{4}{*}{$\begin{array}{l}\text { Çiriş Ekstraktı } \\
(\% 1)\end{array}$} & \multirow{2}{*}{$20 \mathrm{Dk}$} & $20 \mathrm{Dk}$ & 0.61 & $\mathrm{C}$ \\
\hline & & & $30 \mathrm{Dk}$ & 0.59 & $\mathrm{E}$ \\
\hline & & \multirow{2}{*}{$30 \mathrm{Dk}$} & $20 \mathrm{Dk}$ & 0.63 & B \\
\hline & & & $30 \mathrm{Dk}$ & 0.60 & $\mathrm{D}$ \\
\hline & \multirow{4}{*}{$\begin{array}{c}\text { Çiriş Ekstraktı } \\
(\% 3)\end{array}$} & \multirow{2}{*}{$20 \mathrm{Dk}$} & $20 \mathrm{Dk}$ & 0.66 & $\mathbf{A}$ \\
\hline & & & $30 \mathrm{Dk}$ & 0.57 & G \\
\hline & & \multirow{2}{*}{$30 \mathrm{Dk}$} & $20 \mathrm{Dk}$ & 0.58 & F \\
\hline & & & $30 \mathrm{Dk}$ & 0.61 & $\mathrm{C}$ \\
\hline
\end{tabular}




\section{European Journal of Science and Technology}

En yüksek dinamik eğilme direnci $\% 3$ çiriş özütünde 20 dakika vakum $/ 20$ dakika difüzyonda $(0.66 \mathrm{~N} / \mathrm{mm} 2)$, en düşük dinamik eğilme direnci $\% 3$ çiriş özütünde 20 dakika vakum $/ 30$ dakika difüzyonda $(0.57 \mathrm{~N} / \mathrm{mm} 2)$ belirlenmiştir. Bu durum odun türü, anatomik yapı, emprenye maddesi, emprenye türünün dinamik eğilme direnci üzerinde etkili olduğunu söyleyebiliriz. Kontrol örneğine oranla küçükte olsa bir yükselme vardır.

Yapılan bir araştırmada; işlem görmemiş kayında basınç direncinin $\left(60 \mathrm{~N} / \mathrm{mm}^{2}\right.$ ) $)$ belirlendiği [18]. Başka bir çalışmada , Batı Karadeniz sarıçamının basınç direncinin $(518 \mathrm{~kg} / \mathrm{cm} 2)$ tespit edilmiştir 19].

\section{Sonuç}

Deney sonuçlarına gore; en yüksek \% retensiyon \%3 'lük çiriş çözeltisinde 20 dakika vakum 20 dakika difüzyonda (\% 0.43 ),en düşük (\%1) \% retensiyon 20 dakika vakum 20 dakika difüzyonda (\%0.09) tespit edilmiştir. En yüksek dinamik eğilme direnci $\% 3$ çiriş özütünde 20 dakika vakum $/ 20$ dakika difüzyonda $(0.66 \mathrm{~N} / \mathrm{mm} 2)$, en düşük dinamik eğilme direnci $\% 3$ çiriş özütünde 20 dakika vakum 130 dakika difüzyonda $(0.57 \mathrm{~N} / \mathrm{mm} 2)$ belirlenmiştir. Bu durum odun türü, anatomik yapı, emprenye maddesi, emprenye türünün dinamik eğilme direnci üzerinde etkili olduğunu söyleyebiliriz. Kontrol örneğine oranla küçükte olsa bir yükselme vardır.

\section{Kaynakça}

[1] Yiğit, N. ve Benli, M. (2005) Ülkemizde Yaygın Kullanımı Olan Kekik (Thymus vulgaris) Bitkisinin Antimikrobiyal Aktivitesi, Orlab On-Line Mikrobiyoloji Dergisi, 3(8), 1-8.

[2] Çenet, M. ve Toroğlu, S. (2006) Tedavi Amaçlı Kullanılan Bazı Bitkilerin Kullanım Alanları Ve Antimikrobiyal Aktivitelerinin Belirlenmesi İçin Kullanılan Metodlar, KSÜ Fen ve Mühendislik Dergisi, 9(2): 12-20.

[3] Özkan, Z.C., Akbulut, S. (2014) Ormancılık Uygulamaları Ders Notları, Karadeniz Teknik Üniversitesi Orman Fakültesi 1.Trabzon s:1-2

[4Özata, N. (2006) Fitoterapi ve Aromaterapi, Arıtan Yayınları, s:1-8, İstanbul.

[5] Baytop, T. (1984) Türkiye'de Bitkiler ile Tedavi, İstanbul Üniversitesi Yayınları, $\quad$ No3255-Eczacılık $\quad$ Fakültesi $\quad$ No.:40, $\mathrm{s}: 1 .$, İstanbul.

[6] Güler, S. (2004). Erzurum Yöresinde Doğal Yayılış Gösteren Bazı Tıbbi Ve Aromatik Bitkilerin Etnobotanik Etkileri, Çevre ve Orman Bakanlı̆̆ , Yayın No:209, s:1-2,Erzurum.

[7] Çetin,S. (2017) Erzurum İlinde Yetişen Ve Halk Arasında Tıbbi Amaçla Kullanılan Bazı Bitkilerin Antioksidan Ve Antimikrobiyal Aktivitelerinin Belirlenmesi, Artvin Çoruh Üniversitesi, Fen Bilimleri Enstitüsü, Yüksek Lisans Tezi,71 s ,Artvin.

[8] Üstün,S. (2019) Bakır Esaslı Emprenye Maddeleri Ile Muamele Edilen Odunun Doğal Koşullarda Fiziksel Performans Özellikleri Ve Vernikleme Öncesi Bakır Esaslı Emprenye Maddeleri Ile Emprenye Işleminin Fiziksel Performans Özelliklerine Etkisi, Muğla Sitkı Koçman Üniversitesi, Fen Bilimleri Enstitüsü, Yüksek Lisans Tezi, 92 s. Muğla.

[9]TS 53 (1981) Odunun Fiziksel Özeliklerini Tayin Için Numune Alma, Muayene ve Deney Metotları, Ankara.

[10]TS 2470 (1976) Odunda Fiziksel Ve Mekaniksel Deneyler Için Numune Alma Metotları ve Genel Özellikler, Ankara

[11] Atilgan, A., Ersen, N., ve Peker, H. (2013) Different Types Of Wood Treated With Tea Plant Extract Retention Values. Kastamonu University Journal Of Forestry Faculty, 13(2), 278-286

[12] TS 2477 (1976) Odunun Çarpmada Eğilme Dayanımının Tayini, TSE, Ankara

[13]URL-1. 2019.https://bitkiekstresi.wordpress.com/bitki-ekstrakti-nasil-cikarilir

[14] ASTM D 1413-76 (1976) Standartd Methods of Testing Wood Preservatives by Laboratory Soilblock Cultures, Annual Book of ASTM Standarts, USA.

[15] Baysal, E., Yalınkılıç, M.K.(2005) A Comparative Study on Stability and Decay Resistance of Some Environmentally Friendly Fire Retardant Boron Compounds", Wood Science and Technology, (In Press), 122-125.

[16] Tan, H., Peker, H. (2015) Barit Maddesinin Ahşapta Emprenye Edilebilme Özelliği ve Yoğunluk Üzerine Etkisi, Fırat Üniv. Mühendislik Bilimleri Dergisi, Elazığ s.27(1), 29-33.ThermoWood processing”, Journal of Environmental Biology, 31: 1007-1011.

[17] Atilgan, A., Ersen, N., ve Peker, H. (2013) Different Types Of Wood Treated With Tea Plant Extract Retention Values. Kastamonu University ,Journal Of Forestry Faculty, 13(2), 278-286

[18] Bozkurt Y., Erdin, N. (2003) Odun Anatomisi”, İstanbul Üniversitesi Orman Fakültesi Yayınları, İstanbul

[19]Ay, N., Uncu, A. (2004) Murgul Bakır İşletmesi Bacalarından Çıkan SO2 Gazının Sarıçam Odununun Bazı Mekanik Özellikleri Üzerine Etkisi”, Doğu Karadeniz Ormancılık Arastırma Enstitüsü Yayınları, Yayın No:21, Trabzon, S:119. 